\title{
POLUIÇÃO LUMINOSA E EDUCAÇÃO AMBIENTAL: UM ESTUDO DE CASO EM CAMARATE, LISBOA
}

\author{
Inês Nunes ${ }^{1}$ \\ Luís Dourado ${ }^{2}$
}

\begin{abstract}
Resumo: A poluição luminosa resulta de candeeiros e projetores exteriores mal concebidos ou mal direcionados, emitindo luz para além do seu alvo. Além do aspeto económico e energético, a poluição luminosa interfere nos processos naturais da fauna e da flora, na qualidade de vida do Homem e na observação do céu noturno. Considerando a problemática local da poluição luminosa de Camarate, desenvolveu-se um projeto interdisciplinar de Educação Ambiental. Realizaram-se auditorias aos equipamentos de iluminação exteriores, testou-se o efeito da poluição luminosa na visibilidade das estrelas e no desenvolvimento de seres vivos. Os resultados apontam para um nível de poluição luminosa considerável (magnitude 3), na zona da Escola Secundária de Camarate, predominando lâmpadas de sódio de alta pressão e luminárias que apresentam apenas uma semiproteção. Os seres vivos testados, feijoeiros e macroinvertebrados do solo, são afetados pela iluminação artificial noturna, quer ao nível do crescimento, quer nos hábitos de vida, respetivamente.
\end{abstract}

Palavras-chave: Poluição luminosa; Educação ambiental; Luminárias; Constelações; Fatores abióticos.

\section{POLUCIÓN LUMINOSA Y EDUCACIÓN AMBIENTAL: UN ESTUDIO DE CASO EN CAMARATE, LISBOA}

\begin{abstract}
Resumen: La contaminación lumínica resulta de las lámparas y proyectores al aire libre mal diseñados o mal dirigidos, que emiten luz más allá de su objetivo. Además de los aspectos económico y energético, la contaminación lumínica interfiere con los procesos naturales de la fauna y la flora, la calidad de vida del hombre y la visión del cielo nocturno. Teniendo en cuenta el problema local de la contaminación lumínica en Camarate, Lisboa, fue desarrollado un proyecto interdisciplinar de educación ambiental. Se efectuaron auditorías en los accesorios de iluminación al aire libre, probando el efecto de la contaminación lumínica en la visibilidad de las estrellas y el desarrollo de los seres vivos. Los resultados apuntan a un nivel considerable contaminación lumínica (magnitud 3) en la zona de la Escuela Secundaria Camarate, predominantemente debido a lámparas de sodio de alta presión y accesorios que tienen sólo una protección parcial. Los seres vivos que han sido evaluados, las plantas de frijoles y los macro invertebrados del suelo, se ven afectadas por la iluminación artificial, tanto en el nivel de crecimiento como en los hábitos de vida, respectivamente.
\end{abstract}

Palabras clave: Contaminación lumínica; Educación ambiental; Lámparas; Constelaciones; Factores abióticos.

\section{LIGHT POLLUTION AND ENVIRONMENTAL EDUCATION: A CASE STUDY IN CAMARATE, LISBON}

\begin{abstract}
Light pollution results from poorly designed or poorly pointed outdoor lamps and projectors, emitting light beyond their target. Besides the economic and energetic aspects, light pollution interferes with the natural processes of fauna and flora, the quality of human life and the observation of the night sky. Considering the local problem of Camarate, Lisbon light pollution, an interdisciplinary project of Environmental Education was developed. Audits were carried out on external lighting equipment, and the effect of light pollution on the visibility of stars and the development of living beings was tested. The

\footnotetext{
${ }^{1}$ Professora, Ministério da Educação, Portugal. E-mail:< inesolinunes@ gmail.com>.

${ }^{2}$ Universidade do Minho, Instituto de Educação, Portugal. E-mail: <ldourado@ie.uminho.pt>.
} 
results point to a considerable level of light pollution (magnitude 3) in the area of Camarate Secondary School, predominantly from high-pressure sodium lamps and luminaires with only one partial protection. The tested living beings, bean plants and macro invertebrates of the soil, are affected by nocturnal artificial lighting, both in terms of growth and in living habits, respectively.

Keywords: Light pollution; Environmental education; Luminaires; Constellations; Abiotic factors.

\section{Introdução}

\subsection{Causas e consequências da poluição luminosa}

A definição oficial de poluição luminosa provém da Associação Internacional Dark-Sky (IDA) e afirma que este tipo de poluição é qualquer efeito adverso da luz artificial incluindo o brilho do céu, luz invasiva, luz encandeante, diminuição da visibilidade noturna e desperdício de energia.

"A poluição ocorre geralmente em grandes áreas urbanas, reduzindo a visibilidade das estrelas" (LONGCORE; RICH, 2004). A principal causa da poluição luminosa é a iluminação das ruas. Este tipo de poluição ocorre quando a luz está a iluminar na direção errada à qual deveria iluminar (HOLLAN, 2003). O comprometimento da visibilidade do céu noturno não é causado somente pelas luminárias das vias públicas, mas também por outros fatores comuns aos grandes centros urbanos, como a ineficiência na iluminação de outdoors publicitários, estádios de futebol, fachadas de prédios, monumentos, entre outros (GARGAGLIONI, 2009).

Existem três tipos principais de poluição luminosa, que podem ser descritos como: brilho no céu "skyglow", luz ofuscante "glare" e luz intrusa "light trespass". A luz intrusa resulta de um excesso de luz que prejudica a visibilidade. Este tipo de poluição constitui, particularmente, um problema de segurança rodoviária, pois pode causar o encadeamento de condutores, ciclistas ou peões, reduzindo a visibilidade de ruas e sinalética associada. A luz que invade áreas desnecessárias é também um tipo de poluição luminosa - luz intrusiva. Por fim, o brilho do céu, é definido como um brilho alaranjado, em zonas urbanas, causado pela luz que direcionada para cima, é refratada e espalhada pelas partículas da atmosfera reduzindo a visibilidade do céu noturno (PACE, 2000; HOUSE OF COMMONS, 2003; IDA, 2008; THURBER, 2009; RAJKHOWA, 2014).

O interesse pela poluição luminosa tem crescido em vários campos da ciência, estendendo-se desde a astronomia até as ciências ambientais e humanas. Tal como qualquer outro tipo de poluição, esta iluminação desnecessária apresenta consequências não só ao nível do ambiente, mas também na qualidade de vida dos seres vivos, incluindo o ser humano (LONGCORE; RICH, 2004; THURBER, 2009), assim como na economia e, especialmente, no céu noturno, prejudicando as observações astronómicas (GARGAGLIONI, 2007). O impacto da poluição luminosa nos seres vivos é evidenciado em estudos sobre o comportamento e orientação animal, interações competitivas, relações predador-presa, fisiologia animal e comportamento reprodutivo (IDA, 2008). As iluminações artificiais noturnas também podem atrair, fixar ou repelir animais e podem conduzir à extinção local de espécies (LONGCORE; RICH, 2004). As plantas também sofrem com este problema, pois causa um desequilíbrio no processo de fotossíntese (LONGFELLOW, 2009). Além disso, a luz artificial durante a noite pode 
afetar negativamente a saúde humana, aumentando os riscos de cancro e doenças autoimunes e infeciosas (BLASK, 2009; HU et al., 2011), assim como perturbações do sono e do ciclo circadiano (SCHEER et al., 2009; GOOLEY et al., 2010).

De acordo com o Instituto de Astrofísica das Canárias (IAC, 2004), existem vários benefícios em reduzir-se a poluição luminosa, entre eles podem-se citar: reduzir o consumo energético; proteger o meio ambiente noturno, reduzindo as perturbações aos habitats naturais (animais, plantas e processos ecológicos), protegendo aves noturnas, maior segurança no tráfego noturno, aumentar a segurança do transporte aéreo e marítimo e melhorar a qualidade das observações astronómicas.

Considerando as causas da poluição luminosa, a solução para minimizar o problema passa pela substituição dos candeeiros de iluminação pública existentes por outros mais eficientes. Segundo vários estudos (MCCOLGAN, 2007; GARGAGLIONI, 2009; ALMEIDA, 2010; PAZ GÓMEZ et al, 2010; LAN, 2012), existem diferentes tipos de candeeiros que podem ser avaliados consoante o grau de poluição que emitem. Os candeeiros em forma de globo (muito maus) emitem a luz não só para o solo, mas também para o céu noturno, causando muita poluição. O ideal seria que os candeeiros estivessem blindados, direcionando a luz apenas para baixo, para a área que realmente importa iluminar.No entanto, há candeeiros que emitem luz para os lados e para cima, sendo considerados os piores em termos de eficiência e poluição.

Com a descoberta da eletricidade, a humanidade tem vindo a alterar a iluminação natural, não só alterando o padrão natural de foto período, como alterando o tipo de luz a que os seres vivos são expostos (FERNANDES, COELHO, 2010). Segundo os mesmos autores, além do excesso de luz, o uso de lâmpadas (vapor de sódio, vapor de mercúrio, fluorescentes, led, etc.) com espetros diferentes da luz natural potencia efeitos negativos nos seres vivos, que sofrem a influência de luz artificial noturna. A iluminação artificial trouxe grandes benefícios para a humanidade, no entanto o benefício promoveu o aumento do consumo de energia, com emissões de carbono e poluições que põe em risco a vida humana, selvagem e dos ecossistemas (GASTON et al., 2014).

\subsection{Poluição Luminosa e Educação Ambiental}

De acordo com as Nações Unidas, no âmbito da comemoração do Ano Internacional da Luz (2015), é necessário haver uma consciencialização mundial sobre como é que as tecnologias baseadas na luz promovem o desenvolvimento sustentável. $\mathrm{O}$ consumo de energia está na origem de $80 \%$ das emissões de gases com efeito de estufa na União Europeia (UE). É neste contexto que surge a denominada "Estratégia 20-20-20 para 2020" cujo objetivo é reduzir $20 \%$ do consumo de energia, reduzir $20 \%$ das emissões de GEE (Gases com Efeito de Estufa) e que $20 \%$ da energia consumida seja de fonte renovável. Nestes objetivos enquadra-se também a utilização racional de energia e a eficiência energético-ambiental em equipamentos de iluminação pública, através da Estratégia Nacional para a Energia 2020 (Eficiência Energética na Iluminação Pública, 2011).

Por se tratar de um problema ambiental global, a poluição luminosa é objeto de estudo e divulgação de diversas organizações de âmbito local e mundial. Essas organizações são geralmente compostas por cientistas (astrónomos, físicos, biólogos, 
etc), engenheiros, arquitetos, técnicos de iluminação e astrónomos amadores. A maior entidade de divulgação e combate à poluição luminosa no mundo é a International Dark-Sky Association (IDA). Em Portugal a divulgação é realizada sobretudo por associações de astrónomos profissionais e amadores, nomeadamente o Núcleo Interativo de Astronomia (NUCLIO). Esta instituição desenvolve várias ações juntos de professores e alunos divulgando a problemática da poluição luminosa e sensibilizando para a importância da astronomia. Constantes do seu plano anual de atividades inseremse formações creditadas para docentes, entre as quais se destaca "Apagar as estrelas para acender as estrelas", destinada a professores do $1^{\circ}$ ciclo, e "Poluição luminosa eficiência energética e preservação do ambiente", destinada a professores do ensino básico e secundário, da área das Ciências Naturais e Ciências Físico-Químicas, assim como de Geografia. Promove também, entre outros, o projeto internacional DarkSkies Rangers, no qual se desenvolve anualmente um concurso aberto a todas as escolas, sobre a temática da poluição luminosa.

Ao nível da Educação Ambiental formal, a poluição luminosa é um tipo de poluição pouco mencionada nos currículos nacionais e pouco reconhecida pela maioria dos cidadãos. Ao nível de $7^{\circ}$ ano, na disciplina de Físico-Química, o estudo do espaço, prevê que os alunos conheçam e compreendam a constituição do Universo, localizando a Terra, e reconheçam o papel da observação e dos instrumentos na nossa perceção do Universo. No entanto, a prática espontânea de observação do céu noturno é cada vez mais rara e seriamente comprometida com o excesso de luz artificial noturna, sobretudo em zonas urbanas. O programa de $8^{\circ}$ ano de Ciências Naturais inclui, no subdomínio "Ecossistemas", um objetivo geral que é "Compreender a influência das catástrofes no equilíbrio dos ecossistemas". Embora os autores dos manuais de várias editoras abordem diferentes tipos de poluição, não aparece referenciada a poluição luminosa. $\mathrm{Na}$ abordagem da temática da Gestão Sustentável dos Recursos, nomeadamente ao nível dos recursos energéticos, é comum abordarem-se os gastos e desperdícios energéticos, ao nível doméstico, no entanto é rara a abordagem da iluminação pública.

Segundo Bueno (2005), por se manifestar como o maior obstáculo à prática da observação astronómica e, consequentemente, à utilização do céu noturno como espaço de observação de fenómenos físicos de interesse científico e educacional, a poluição luminosa constitui um importante campo para a pesquisa e divulgação no intuito de encontrar soluções que diminuam este tipo de degradação ambiental e promovam a melhor utilização dos recursos tecnológicos utilizados na iluminação artificial. Várias pesquisas demonstram a importância da inserção da Astronomia no ensino formal, sugerindo que esta possui caráter motivacional; trata de fenómenos quotidianos; está presente nos meios de comunicação social, nos quais são frequentemente discutidas as descobertas astronómicas (KANTOR, 2001; GAMA; HENRIQUE, 2010; LANGHI; NARDI, 2011).

Neste sentido, Kantor (2001) aponta que esta ciência não pode ser apenas somada ao currículo, contribuindo, ainda mais, para a fragmentação do conhecimento. Segundo o autor, uma abordagem aplicável seria a articulação da Astronomia com as disciplinas regulares do currículo. Conforme Gama \& Henrique (2010), a Astronomia, quando apenas acrescentada às disciplinas de forma superficial, não potencializa uma problematização adequada e nem permite uma abordagem por meio de temáticas motivadoras. Nesta direção, os resultados de pesquisas no Ensino de Física apontam, como possibilidade, a reconfiguração do currículo escolar com base em temas, 
destacando que tal modalidade de ensino permite: a contextualização e a interdisciplinaridade (DELIZOICOV; ANGOTTI; PERNANBUCO, 2002), inserir problemáticas pertencentes à realidade do indivíduo (DELIZOICOV, 1983) e abordar questões com enfoque na Ciência, Tecnologia e Sociedade (SANTOS; MORTIMER, 2002).

Além de prejudicar a visibilidade do céu noturno, a poluição luminosa tem chamado a atenção de biólogos e grupos de defesa do ambiente, pelo facto de se revelar prejudicial à sobrevivência de animais de hábitos noturnos, principalmente aves durante períodos migratórios, tartarugas marinhas, répteis, anfíbios e insetos (BUENO, 2005).

Considerando a poluição luminosa como um tema ambiental, a sua abordagem deve procurar criar sempre situações que facilitem a participação e a intervenção tanto na identificação quanto na resolução de problemas que se reflitam na realidade envolvente, sendo desta forma a vida real a base do ensino-aprendizagem (AMPARO, 2007). Segundo Almeida (2007), a Educação Ambiental tem como finalidade desenvolver uma responsabilidade ambiental, traduzida num sentido de participação e empenhamento na resolução dos graves e complexos problemas ambientais que ameaçam a qualidade e a manutenção da vida humana e a de outras espécies. A implementação do projeto "Caso Camarate - Investigação Luminosa" ao contribuir para que os alunos, ao longo do ano, adquirissem conhecimentos $\mathrm{e}$ desenvolvessemcompetências necessárias para o exercício de uma cidadania ambiental, relacionada com a problemática da poluição luminosa, contribuiu, desde modo, para a Educação Ambiental.

\subsection{Objetivos do projeto "Caso Camarate - Poluição Luminosa"}

A Escola Secundária de Camarate está integrada no Programa Territórios Educativos de Intervenção Prioritária (TEIP), sendo a rentabilização dos recursos, a capacidade de mobilizar parceiros e o trabalho em rede no âmbito social contributos para a valorização da escola no meio. Atendendo à localização urbana da Escola Secundária de Camarate, concelho de Loures - Lisboa, e à sua proximidade a infraestruturas rodoviárias e aeroportuárias, partiu-se de um problema real de existência de poluição luminosa, identificado pelos alunos. Foi neste contexto que surgiu o projeto "Caso Camarate - Investigação luminosa", cuja implementação foi impulsionada pelos seguintes objetivos: sensibilizar para a problemática da poluição luminosa; realizar auditoria à luz artificial noturna que incide sobre Camarate; demonstrar o efeito da poluição luminosa nas observações do céu noturno e construir mapas locais de poluição luminosa; testar o efeito da poluição luminosa sobre os seres vivos; divulgar a investigação e apresentar plano de ação junto da comunidade escolar, extraescolar e governantes locais.

Todos estes objetivos foram concretizados no ano 2015/2016 ao nível local. No entanto, sendo a poluição luminosa uma temática de educação ambiental requer uma continuidade a longo prazo, que se traduz por alargar a outras zonas do concelho, do distrito e do país a auditoria à luz artificial noturna, de modo a aumentar a área mapeada quanto à poluição luminosa, assim como continuar a trabalhar junto dos governantes locais de modo a alertar para a problemática e propor medidas de mitigação. 
A temática da poluição luminosa apresentou uma mais-valia ao nível da articulação nos conselhos de turma, constituindo um projeto interdisciplinar, integrando diferentes saberes, nomeadamente na área das Ciências Físico-Químicas, Matemática, Ciências Naturais e Tecnologias da Informação e Comunicação. Deste modo, pretendeu-se desenvolver uma metodologia de aprendizagem baseada na resolução de problemas, incentivando o gosto pela investigação científica em jovens estudantes do $3^{\circ}$ ciclo.

\section{Implementação do projeto}

A implementação do projeto "Caso Camarate: Investigação Luminosa" iniciouse com a sensibilização de alunos, de três turmas de $7^{\circ}$ e a uma turma de $8^{\circ}$ ano, para a temática da poluição luminosa. Perante um cenário de poluição luminosa, como problema crescente, devido a luminárias ou projetores mal concebidos ou direcionados, iluminando para cima e para os lados, emitindo luz muito para além do seu alvo, sem qualquer efeito útil, os alunos definiram, numa primeira fase, várias questões problema, relacionadas com o meio envolvente à escola e às suas casas. Promoveu-se a elaboração de hipóteses e definição de estratégias que permitissem dar resposta às questões problema. A implementação consistiu então na realização das atividades ao longo do ano letivo 2015/2016, que são descritas de seguida.

\subsection{Realização de auditoria à iluminação externa da Escola Secundária de Camarate e a ruas de Camarate}

O trabalho foi efetuado durante os meses de janeiro e fevereiro de 2016. Para a realização da auditoriafoi fornecido aos alunos um guião "Auditoria à iluminação pública" (Anexo A), que foi analisado, tendo-se solicitado o seu preenchimento e apresentação dos resultados à turma. A análise dos resultados foi conseguida com a colaboração da disciplina de Ciências Físico-Químicas e das Novas Tecnologias da Informação e Comunicação (TIC). Os resultados foram analisados por cada turma participante (turmas de $7^{\circ}$ e $8^{\circ}$ ) e posteriormente foi feita uma análise global dos resultados nas aulas de TIC, com uma turma de $8^{\circ}$ ano. Esta turma fez ainda a divulgação das auditorias e dos resultados globais obtidos a todas as turmas de $9^{\circ}$ ano, no âmbito da disciplina de Ciências Físico-Químicas, cujo tema em estudo nessa altura consistia nos "Efeitos da corrente elétrica e energia elétrica".

\subsection{Divulgação e participação na campanha "Globeat Night"}

Depois da análise e divulgação das auditorias realizadas, iniciou-se a promoção da campanha Globeat Nigth, explorando como recursos o Stellarium e a página da internet dessa campanha ${ }^{3}$. Os alunos recolheram dados relativamente à constelação de Orion (Figura 1), tendo-se participado na campanha de 1 a 10 de março de 2016, recorrendo ao guião da atividade disponibilizado pelo site.

\footnotetext{
${ }^{3}$ Disponível em: 〈http://www.globeatnight.org/5-steps.php〉.
} 


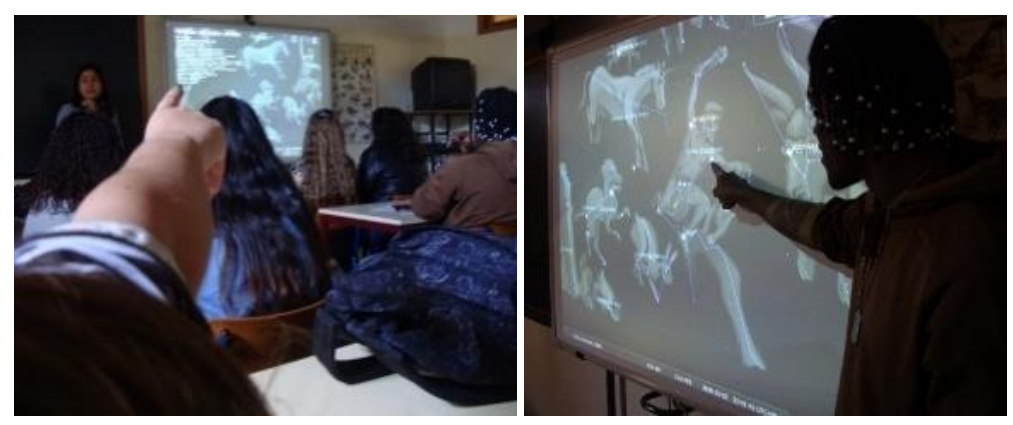

Figura 1 - Exploração do software Stellarium e treino da observação da constelação de Orion.

\subsection{Realização de atividades experimentais sobre a influência da luz artificial noturna no desenvolvimento dos seres vivos}

Para testar o efeito da luz artificial noturna em seres vivos, procedeu-se à realização de atividades experimentais, com controlo de variáveis, através da implementação integrada de atividades laboratoriais e de campo. Optou-se pelo uso de feijoeiros, plantas de crescimento rápido, para testes com plantas, e macroinvertebrados do solo, para testes com animais, pois ao nível do $8^{\circ}$ ano abordava-se a importância do solo nos ecossistemas. Colocaram-se vasos com sementes de feijão (4 réplicas) debaixo de uma luminária e outros quatro vasos afastados de luminárias (Figura 2). Cada vaso possuía 4 sementes de feijão. Durante 6 semanas, os feijoeiros foram observados e seguidos quanto ao seu crescimento. Os feijoeiros foram medidos semanalmente, tendose calculado a sua média em centímetros.
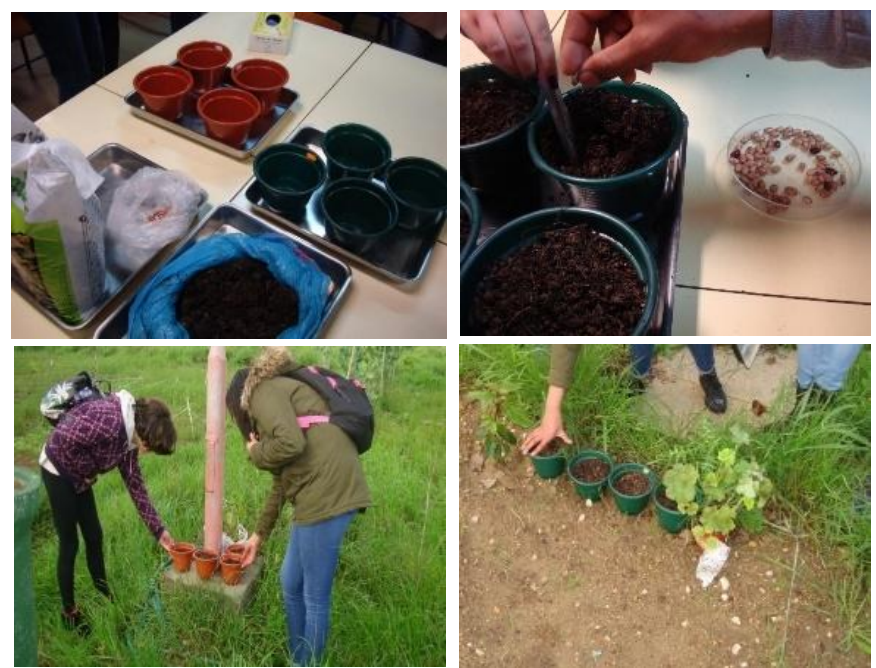

Figura 2 - Atividades experimentais sobre a influência da luz artificial noturna no desenvolvimento de plantas (feijoeiro).

No que concerne ao estudo da influência da luz artificial noturna nos macroinvertebrados do solo, engenhou-se uma armadilha para recolher estes seres vivos. Usaram-se então copos de plástico, contendo álcool (3/4 do copo) e algumas gotas de vinagre. Estes copos foram enterrados, de modo a que a sua borda ficasse ao mesmo nível que o solo. Tapou-se a abertura do copo, com pedaços de garrafão de plástico, garantindo que não saíssem desse local e que proporcionavam aberturas 
laterais, por onde os macroinvertebrados pudessem passar (Figura 3).

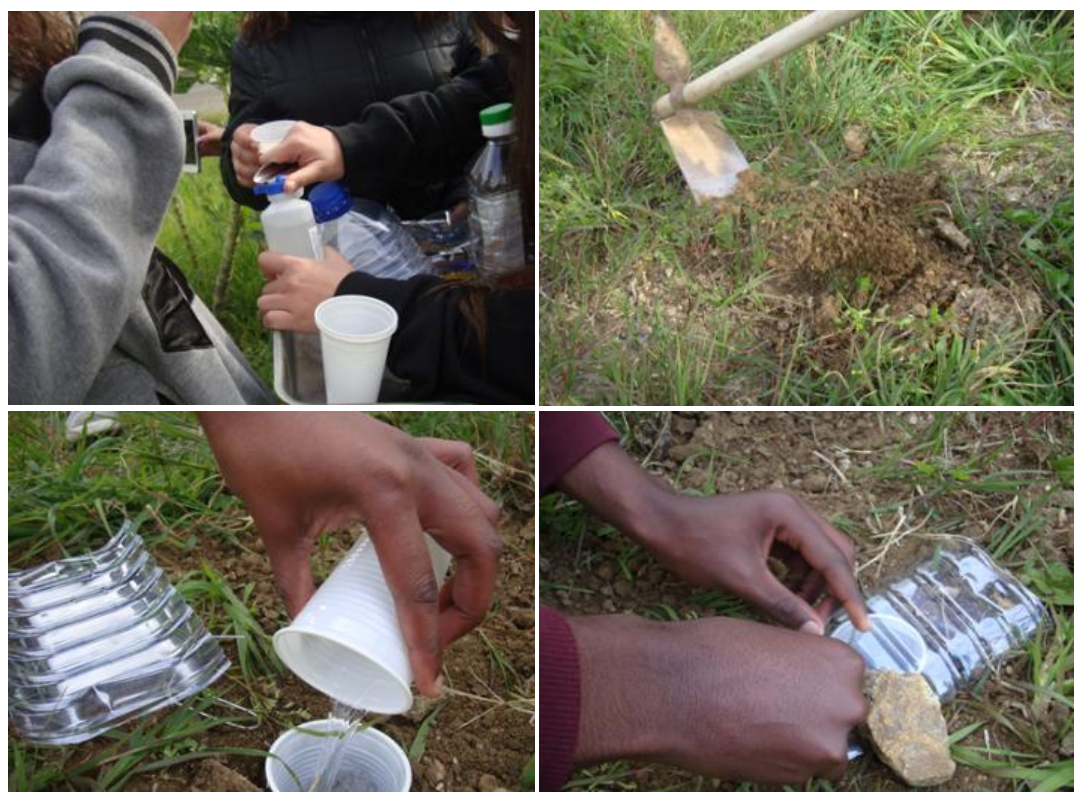

Figura 3 - Montagem de armadilhas debaixo de luminária e afastadas das luminárias, para recolher macroinvertebrados do solo.

A atividade experimental consistiu em colocar três armadilhas numa zona com luz artificial noturna, junto a uma luminária existente, tendo como controlo o mesmo número de armadilhas colocadas numa zona afastada de luminárias. Passadas duas semanas, as armadilhas foram recolhidas, para identificação, em laboratório, dos macroinvertebrados que continham (Figura 4).
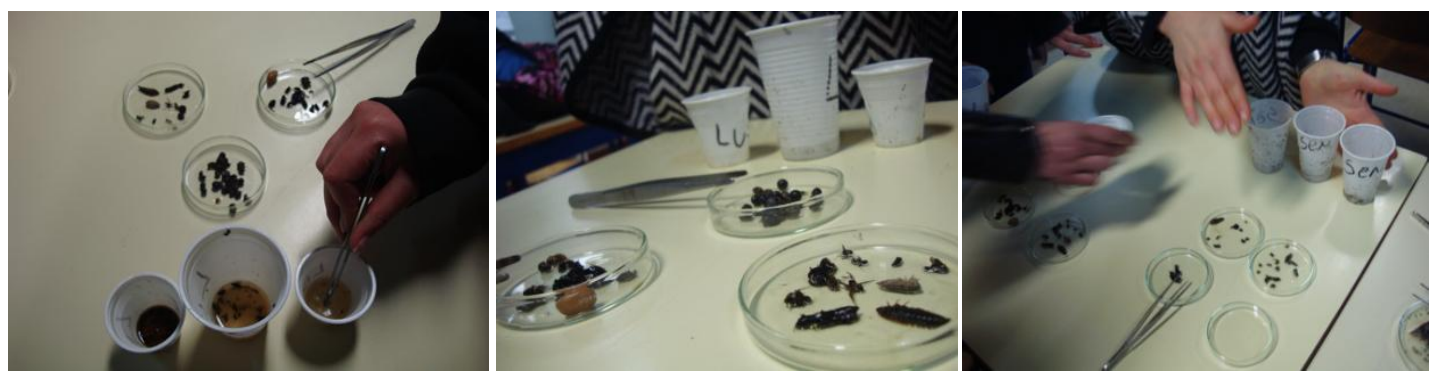

Figura 4 - Atividade laboratorial de separação, contagem e identificação de macroinvertebrados do solo, recolhidos nas armadilhas com e sem luz artificial noturna.

Na realização dos testes de influência de luz artificial noturna nos seres vivos, os alunos, mais do que a obtenção dos resultados, tiveram a oportunidade de desenvolver percursos investigativos. Ainda que, ao nível do programa de Ciências Naturais do $8^{\circ}$ ano, seja prevista a realização de atividades experimentais, com o desenvolvimento do projeto "Caso Camarate:Investigação Luminosa", os alunos tiveram de definir as suas próprias atividades e não se limitaram a cumprir protocolos preestabelecidos nos manuais escolares. 


\subsection{Divulgação e participação no concurso internacional Dark Skies Rangers Cartoon, promovido pelo NUCLIO - Núcleo Interativo de Astronomia}

No mês de abril iniciou-se a promoção do concurso "Dark Sky Rangers Cartoon". Os alunos elaboraram bandas desenhadas/cartoons sobre poluição luminosa. Os melhores trabalhos tiveram de ser submetidos até ao dia 27 de maio. Nesta atividade os alunos tiveram possibilidade de refletir e transmitir uma mensagem sobre as causas e consequências da poluição luminosa.

\subsection{Realização de Atividades Hands-on - Construção de espetroscópios e análise de espetros de várias fontes de luz}

Aquando da realização da auditoria à iluminação artificial noturna, para efeitos de cálculo de energia gasta pelas luminárias, os alunos tiveram que pesquisar sobre o tipo de lâmpadas existentes (por exemplo: vapor de sódio, vapor de mercúrio, halogénio, LED). Na pesquisa, analisaram estudos que indicam que a exposição a certos espetros da luz artificial noturna, diferentes do espetro da luz natural, são prejudiciais para a saúde e para o ambiente. Fazia sentido, então, num contexto interdisciplinar, realizar um estudo mais aprofundado da luz.

A escola foi inscrita como Escola Piloto nos projetos europeus dinamizados pelo NUCLIO. Os formadores da NUCLIO, no dia 11 de maio, proporcionaram a construção de um espetroscópio a alunos de $8^{\circ}$ ano. Este momento revelou-se de grande interesse por parte dos alunos, pela possibilidade de construírem um aparelho artesanal com uma rede de difração, capaz de separar os comprimentos de onda da luz e de obterem espetros de luz (Figura 5). A atividade coincidiu com a abordagem do tema "Luz" na disciplina de Ciências Físico Químicas e possibilitou a visualização de espetros de vários tipos de lâmpadas (por exemplo: espetro contínuo de lâmpada incandescente e espetro descontínuo de lâmpada de sódio).Analisando o espetro de diferentes tipos de lâmpadas, os alunos puderam comparar o espetro das lâmpadas identificadas à sua eficiência energética e ainda relacionar os espetros visualizados com o espetro da luz solar.
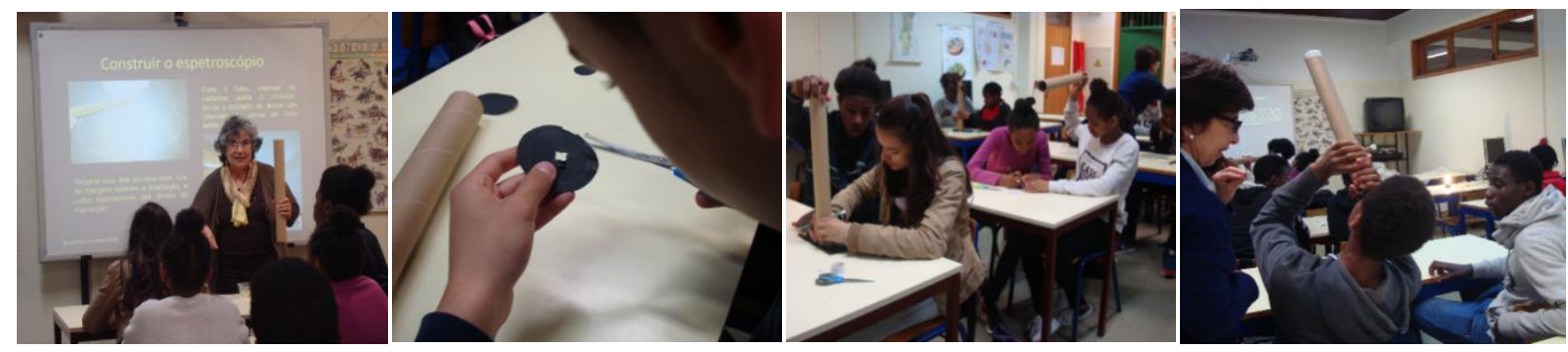

Figura 5 - Realização de Atividades Hands-on - Construção de espetroscópios e análise de espetros de várias fontes de luz. 


\subsection{Implementação da metodologia Inquiry Based Learning (Escolas Piloto de Projetos Europeus)}

Embora ao longo da execução do projeto "Caso Camarate: investigação Luminosa" tenha sido desenvolvida uma metodologia baseada na resolução de problemas, a utilização da metodologia Inquiry, recorrendo à plataforma europeia Inspiring Science Education, foi apenas testada através da aplicação de umcenário educativo em alunos de $7^{\circ}$ ano no mês de maio (Figura 6). No dia 11 de maio o projeto foi apresentado num encontro promovido pela Escola Secundária de Camarate Escol[h]as Práticas III, para partilha de boas práticas entre várias escolas do concelho de Loures, tendo ocorrido também neste dia uma formação para professores intitulada, "Como criar uma aula online segundo a metodologia Inquiry Based Learning" (Figura 7).

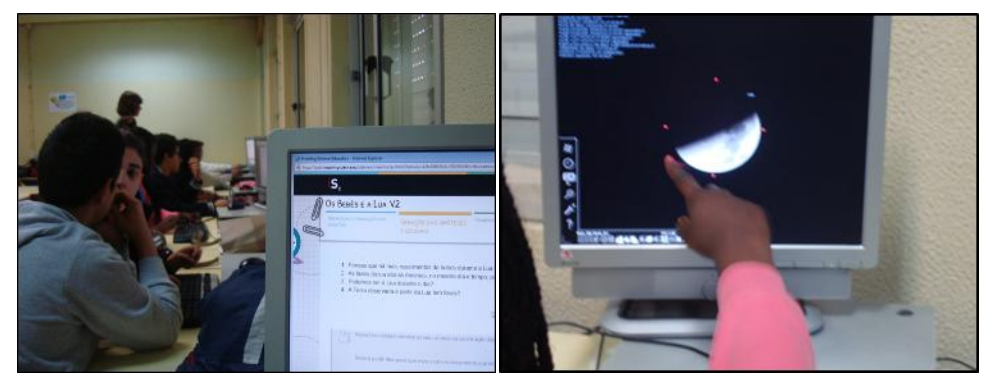

Figura 6 - Aplicação de cenário educativo "Os bebés e a lua”, a alunos de $7^{\circ}$ ano.
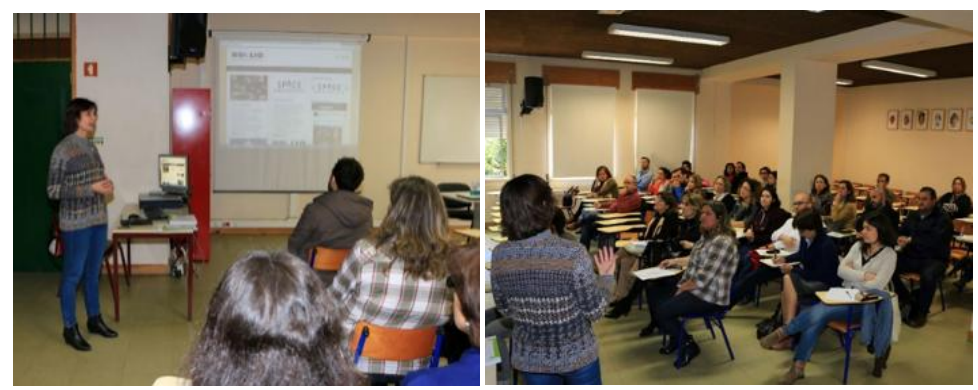

Figura 7 - Palestra a professores: "Como criar uma aula online seguindo a metodologia Inquiry.", dinamizada pelo NUCLIO.

A aplicação desta metodologia implica uma ação participativa dos alunos, prevendo a passagem por várias fases, características do método científico. Pela aplicação do cenário "Os Bebés e a Lua", verificaram-se as conceções alternativas que os alunos apresentam sobre o tema, elaboraram-se questões problema e hipóteses. Para testar as suas hipóteses exploraram o programa Stellarium. Nas fases finais procedem à comparação dos resultados obtidos com as hipóteses, podendo chegar a conclusões ${ }^{4}$. Este método permite ao professor acompanhar a evolução da turma, ao nível das respostas dadas, fazendo o seu tratamento estatístico. Neste caso, o professor sabe quem está a ter mais dificuldade na execução do percurso investigativo. Esta metodologia é uma alternativa ao tradicional relatório científico solicitado aos alunos, sobretudo nas

\footnotetext{
${ }^{4}<\underline{\mathrm{http}}$ ///tools.inspiringscience.eu/delivery/lesson/index?id=2aa55fcb \&t=s$>$.
} 
disciplinas de Ciências, poupando papel e tempo.

\subsection{Realização de observação astronómica na escola aberta à comunidade educativa}

No dia 17 de junho o projeto, desenvolvido ao longo do ano letivo, culminou com uma observação noturna aberta a toda a comunidade educativa, especialmente para as turmas que participaram e suas famílias. Com esta atividade pretendeu-se dar a conhecer como seria o céu noturno de Camarate sem poluição luminosa, numa palestra recorrendo ao programa Stellarium, e posteriormente comparou-se com céu noturno existente, através de telescópios.A ação consistiu num alerta acerca da temática da poluição luminosa e importância da astronomia, sobre a qual a maioria dos cidadãos não está consciencializado.

\subsection{Parcerias}

O Núcleo Interativo de Astronomia (NUCLIO) dinamiza formações sobre poluição luminosa e eficiência energética. Apoiou todas as fases do projeto "Caso Camarate: Investigação Luminosa", uma vez que a professora coordenadora do projeto estava a frequentar uma dessas ações. Além do esclarecimento de questões científicas, partilhou material para aplicar em contexto escolar, nomeadamente Kit de poluição luminosa, e forneceu material para a construção de espetroscópios.

A Camara Municipal de Loures destacou-se pelo apoio técnico e divulgação do projeto. Ao nível da divulgação, o projeto foi apresentado o dia 16 de fevereiro à vereadora da educação da Câmara de Loures, a qual mostrou recetividade no tema como projeto educativo alargado a outras escolas. Uma vez que a temática se insere na educação ambiental, remeteu nova reunião com engenheiros do departamento de obras públicas e energia, pelo que a mesma se realizou o dia 6 de abril. Nesta reunião, pediuse a validação dos dados. Um dos engenheiros presentes na reunião esteve posteriormente na escola, para verificar pessoalmente o tipo de lâmpadas existentes, tendo fornecido o documento de referência sobre iluminação pública e eficiência energética.

Nos dias 14 e 15 de abril, o projeto "Caso Camarate - Investigação Luminosa" foi divulgado na exposição Mostrarte, uma mostra dos projetos escolares e socioeducativos que se realizam em espaços educativos do concelho de Loures. Para a mostra do projeto, além de um PowerPoint a descrever o projeto e os resultados obtidos, estavam disponíveis quatro atividades interativas, relacionadas com a temática da poluição luminosa.

Através do apoio da Câmara Municipal de Loures, foi possível realizar uma visita de estudo a uma fábrica de construção de luminárias "Schréder Iluminação SA", no dia 25 de maio, com o objetivo de conhecer a tecnologia utilizada e fatores a ter em atenção na iluminação pública. 


\section{Resultados}

\subsection{Realização de auditoria à iluminação externa da Escola Secundária de Camarate e a ruas de Camarate}

Como resultado das auditorias foram identificadas e caraterizadas, por todos os alunos participantes, 193 luminárias nas ruas de Camarate e 32 luminárias ao nível do recinto da escola. Os dados recolhidos na auditoria à iluminação exterior da escola foi validada por engenheiros da Câmara Municipal de Loures. A Escola Secundária de Camarate apresenta três tipos de luminárias, possuindo predominantemente lâmpadas de alta pressão de sódio, que emitem cor alaranjada (Figura 8).

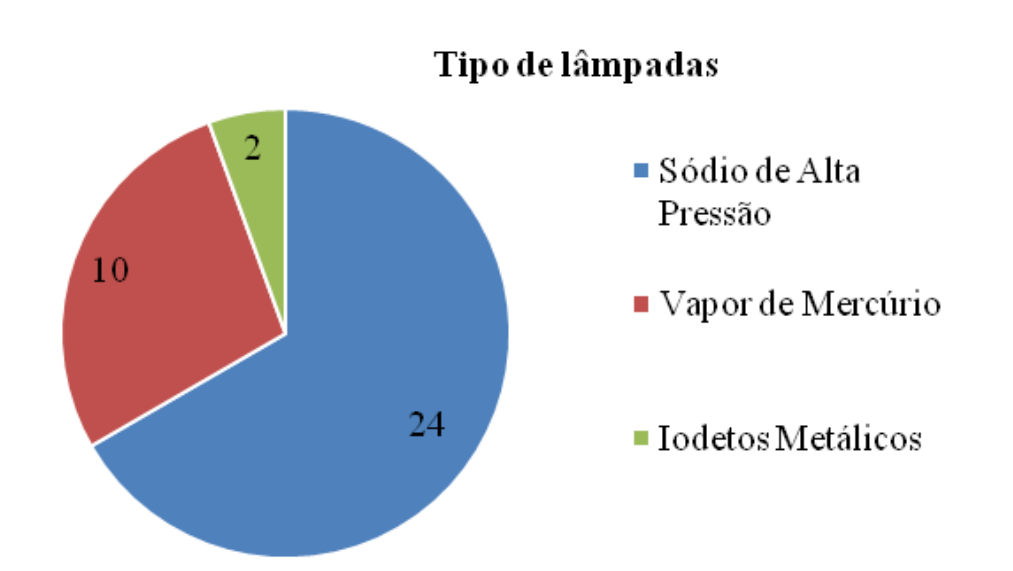

Figura 8 - Tipos de lâmpadas registadas na auditora às luminárias externas da Escola Secundária de Camarate.

Estas luminárias têm uma semicobertura, que não é suficiente para direcionar a luz para o chão, havendo ainda desperdício de luz para os lados e para cima (Tabela 1). A escola sofre influência da iluminação das ruas envolventes e do eixo Norte-Sul, que passa num terreno contíguo à escola, a oeste. Se as lâmpadas da escola fossemsubstituídas pelo sistema LED, havia uma poupança muito significativa no custo total da iluminação $(86,9 \%, 76 \%$ e 93\%), relativamente às lâmpadas de vapor de sódio,

\begin{tabular}{|c|c|c|c|c|}
\hline $\begin{array}{c}\text { Total de } \\
\text { lâmpadas }\end{array}$ & \multicolumn{2}{|c|}{ Proteção da lâmpada } & $\begin{array}{c}\text { Frequência } \\
\text { relativa }\end{array}$ & $\begin{array}{c}\text { Frequência } \\
\text { absoluta }\end{array}$ \\
\hline \multirow{3}{*}{36} & Sem proteção & Muito Mau & 0 & - \\
\cline { 2 - 5 } & Com semiproteção & Mau/Satisfatório & $\mathbf{3 4}$ & $\mathbf{9 4 , 4 \%}$ \\
\cline { 2 - 5 } & Com proteção & Ótimo & 2 & $15,6 \%$ \\
\hline
\end{tabular}

vapor de mercúrio e de iodetos metálicos, respetivamente (Tabelas 2 e 3).

Tabela 1 - Caraterização das luminárias quanto à proteção da lâmpada. 
Poluição luminosa e educação ambiental: um estudo de caso em Camarate, Lisboa

\begin{tabular}{|c|c|c|c|c|c|c|c|}
\hline Lâmpada & $\begin{array}{l}\text { Potência } \\
\text { (W) }\end{array}$ & $\begin{array}{c}\mathbf{N}^{\circ} \text { horas } \\
\text { de } \\
\text { uso/dia }\end{array}$ & $\begin{array}{c}N^{0} \text { horas } \\
\text { de uso } \\
\text { /ano }\end{array}$ & $\begin{array}{c}\text { Energia } \\
\text { utilizada } \\
\text { num ano } \\
(\text { Wh })\end{array}$ & $\begin{array}{c}\text { Energia } \\
\text { (KWh) }\end{array}$ & $\begin{array}{c}\text { Custo da } \\
\text { iluminação } \\
\text { exterior } \\
\text { /ano (euros) } \\
1 \mathrm{KWh}= \\
0,14 \text { euros } \\
\end{array}$ & $\begin{array}{c}\text { Custo da } \\
\text { iluminação } \\
\text { exterior } \\
\text { num dia } \\
\text { (euros) }\end{array}$ \\
\hline $\begin{array}{c}\text { Alta Pressão } \\
\text { de Sódio }\end{array}$ & 100 & 12 & 4380 & 438000 & 438,0 & 61,32 & 0,168 \\
\hline $\begin{array}{l}\text { Vapor de } \\
\text { Mercúrio } \\
\end{array}$ & 125 & 12 & 4380 & 547500 & 547,5 & 76,65 & 0,210 \\
\hline $\begin{array}{c}\text { Iodetos } \\
\text { Metálicos }\end{array}$ & 400 & - & 12 & 4800 & 4,8 & 0,67 & 0,002 \\
\hline LED & 30 & 12 & 4380 & 131400 & 131,4 & 18,40 & 0,050 \\
\hline
\end{tabular}

Tabela 2 - Comparação dos gastos de cada lâmpada existente na Escola Secundária de Camarate com o gasto de uma lâmpada de Emissão de Luz Díodo (LED).

\begin{tabular}{|c|c|c|c|}
\hline Poupança & $\begin{array}{c}\text { LED/AIta Pressão de } \\
\text { Sódio }\end{array}$ & $\begin{array}{c}\text { LED/Vapor de } \\
\text { Mercúrio }\end{array}$ & $\begin{array}{c}\text { Led/Iodetos } \\
\text { Metálicos }\end{array}$ \\
\hline Euros & 42,92 & 58,25 & 0,62 \\
\hline Percentagem & $70 \%$ & $76 \%$ & $93 \%$ \\
\hline
\end{tabular}

Tabela 3 - Poupança (em euros e em percentagem) na s substituição das lâmpadas existentes por lâmpadas LED.

A realização da auditoria às ruas de Camarate consistiu na recolha de informação da zona de residência dos alunos, englobando vários bairros locais. Das 193 luminárias identificadas $64 \%$ correspondem a lâmpadas de sódio de alta pressão, $27 \%$ a lâmpadas de sódio de baixa pressão, $7 \%$ a lâmpadas de vapor de mercúrio e apenas $2 \%$ a lâmpadas LED. Relativamente à proteção da lâmpada verificou-se que $73,1 \%$ apresenta apenas uma semiproteção, havendo muito desperdício de luz e energia.

\subsection{Divulgação e participação na campanha "Globeat Night"}

Os alunos recolheram dados relativamente à visibilidade da constelação de Orion na zona de Camarate. A Figura 9 representa o mapa do céu noturno local, onde é possível identificar algumas estrelas da constelação de Orion, tendo-se registado um predomínio do padrão de magnitude 3. A magnitude é a escala logarítmica do brilho de um objeto utilizada na astronomia. Quanto mais baixos forem os níveis de magnitude maior é o grau de poluição luminosa. Deste modo, a zona de Camarate apresenta poluição luminosa considerável. Os resultados submetidos pelos alunos estão disponíveis online, explorando os dados de 2016, na página ${ }^{5}$ (Figura 10). Esta plataforma permite comparar os resultados submetidos de outros locais do planeta, relativamente ao grau de poluição luminosa. Em Portugal registraram-se muito poucas submissões.

\footnotetext{
${ }^{5}<$ http://www.globeatnight.org/map $>$.
} 


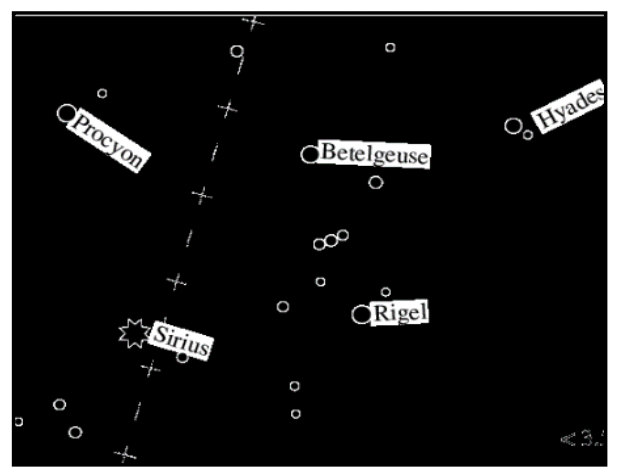

Figura 9 - Mapa do céu noturno, na zona de Camarate, onde é possível identificar algumas estrelas da constelação de Orion (magnitude 3).

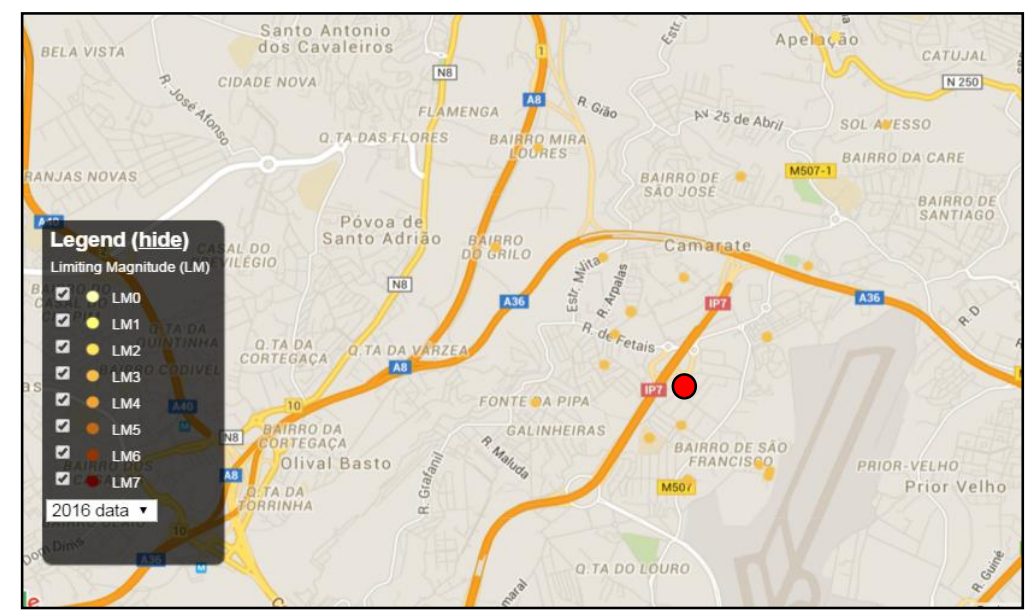

Figura 10 - Mapa de poluição luminosa da zona envolvente à Escola Secundária de Camarate, construído pela submissão de dados referentes à campanha de 1 a 10 de março do programa Globeat Nigth. OEscola Secundária de Camarate.

\subsection{Realização de atividades experimentais sobre a influência da luz artificial noturna no desenvolvimento dos seres vivos}

$\mathrm{Na}$ atividade experimental para testar a influência da luz artificial noturna em plantas, verificou-se que com luz artificial noturna os feijoeiros germinaram e cresceram mais rapidamente (Figura 11). Passados 30 dias apareceram flores apenas nos feijoeiros com luz artificial noturna.

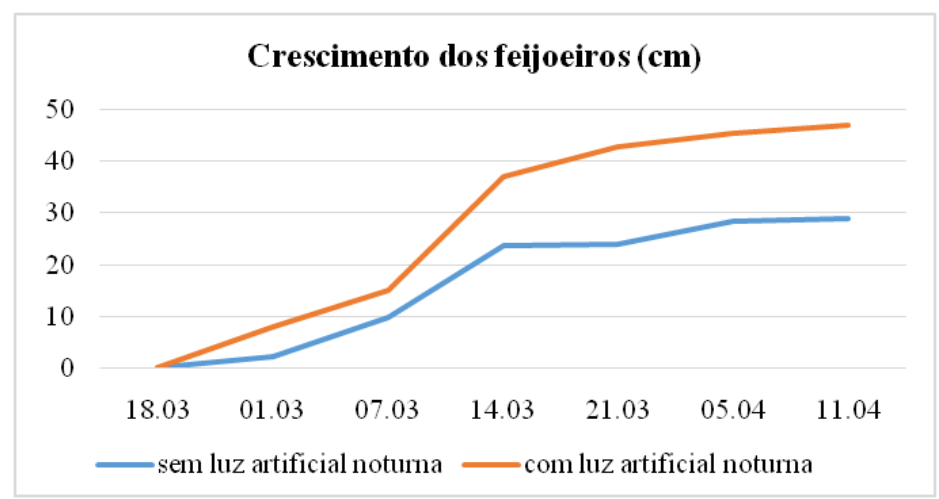

Figura 11 - Crescimento de feijoeiros com e sem luz artificial noturna. 
No que concerne ao estudo da influência da luz artificial noturna nos macroinvertebrados do solo, contrariamente aos resultados esperados foi encontrada uma maior diversidade e quantidade de macroinvertebrados nas armadilhas expostas à luz artificial noturna. Possivelmente o efeito térmico da luz sobrepôs-se à tendência lucífuga dos invertebrados do solo, uma vez que a atividade foi realizada com condições de temperatura desfavoráveis para alguns destes seres vivos. Verificou-se que é necessário encurtar o tempo de exposição das armadilhas, para que a fauna recolhida esteja em bom estado de identificação. Por este motivo fez-se a separação com base nas semelhanças morfológicas gerais, sem se ter conseguido estudar características específicas que permitiriam chegar à classe.

\subsection{A Educação Ambiental no projeto "Caso Camarate Investigação Luminosa"}

Não existe um real cadastro da iluminação pública, na grande maioria das Câmaras Municipais. Para saber gerir é necessário conhecer o que existe. Não sabendo o que existe é difícil fazer a sua gestão. Não sabendo onde estão os gastos não se pode saber como diminui-los. Neste contexto, as escolas e respetivos alunos ao realizar auditorias à iluminação pública, podem ser parceiros das autarquias e municípios, desenvolvendo-se assim uma cidadania responsável e ambiental.

A construção de mapas de poluição local e sua comparação com outras zonas do planeta, através da plataforma do programa Globeat Nigth, constitui uma ferramenta de utilidade, que permite ter uma perceção da poluição luminosa em termos geográficos e ao longo do tempo. No entanto, Portugal apresenta poucos participantes a submeter dados, pelo que dada a relevância do tema, o programa devia ter hiperligação nos sites de Câmaras Municipais, Escolas, entidades associadas à preservação do ambiente, desenvolvendo-se (in)formações para a divulgação do mesmo.

Importa referir que a luz artificial noturna pode ser prejudicial ao desenvolvimento das plantas que existem na natureza, alterando o seu ciclo de vida. Por exemplo, luz incidente em árvores ou hortas durante toda a noite faz com que as plantas tenham folhas, flores e frutos fora da época normal, fenómenos que vão afetar outros seres vivos do ecossistema. Contudo, o teste da influência da luz artificial noturna no desenvolvimento dos feijoeiros reveste-se de interesse, pela possibilidade de acelerar crescimento de plantas, florescência ou produção de fruto, na área de produção agrícola ou de plantas ornamentais. A existência de algumas estufas, por exemplo, permite o controlo do fotoperíodo. O tipo de lâmpadas, os seus espectros, a sua temperatura são fatores que também podem ser estudados pelos alunos, em outras atividades práticas. Estas permitiriam uma implementação de trabalho laboratorial e de campo, numa articulação horizontal entre Ciências Naturais e Ciências Físico-Químicas.

No programa de $8^{\circ}$ ano de Ciências Naturais existe no subdomínio "Ecossistemas" um objetivo geral que é "Compreender a influência das catástrofes no equilíbrio dos ecossistemas". Embora os autores dos manuais de várias editoras abordem diferentes tipos de poluição, não aparece referenciada a poluição luminosa. Por outro lado, a técnica de captação de macroinvertebrados do solo, usada no projeto, pode constituir um modelo de atividade prática para outras escolas, no âmbito do estudo do solo. Estas atividades têm cabimento também no âmbito da realização da influência dos fatores abióticos nos seres vivos, pelo que podem diversificar os recursos já existentes. 
Neste contexto, o projeto "Caso Camarate: investigação luminosa" possibilitou um trabalho didático dos conteúdos ambientais do programa educativo, com aplicações reais, através de ações concretas. Numa perspetiva pedagógica, a Educação Ambiental não constitui um desafio fácil para o professor, obrigando-o a questionar-se como levar à prática uma verdadeira Educação Ambiental. A possibilidade de aplicar cenários educativos, em plataformas de projetos europeus como é o caso do Inspiring Science Education, aplicando a metodologia "Inquiry" é uma mais-valia, pelos recursos já existentes e pela metodologia interativa, na qual o aluno é ajudado a construir o seu conhecimento.

\section{Considerações finais}

O conhecimento sobre o meio constrói-se a partir das vivências, experiências que envolvam a resolução de problemas, a conceção e desenvolvimento de projetos e a realização de atividades de investigação. Neste contexto, o projeto "Caso Camarate: Investigação Luminosa" apresentou relevância científica e pedagógica pelas seguintes razões:

- Permitiu abordar temáticas do currículo escolar do $3^{\circ}$ ciclo, recorrendo a uma metodologia de projeto, baseada na resolução de problemas, em detrimento de métodos tradicionais. Verificou-se que este projeto ajudou a cativar muitos alunos para a temática da poluição luminosa, uma vez que estes se sentiram como investigadores, recolhendo e analisando dados, que seriam alvo de análise posterior pela direção e governantes locais.

- Permitiu articulação horizontal, promovendo-se articulação interdisciplinar no mesmo nível de ensino e nos Conselhos de Turma, e articulação vertical, pela colaboração entre turmas de anos de escolaridade diferentes.

- Permitiu a implementação de atividades práticas diversas, entre as quais se salientam as experimentais, com controlo de variáveis, nas quais foi possível integrar atividades de campo e de laboratório.

- A temática é relativamente simples de tratar, pela existência de factos que os alunos de todos os níveis de ensino podem presenciar associados à poluição luminosa. Esta temática pode ser divulgada a outras escolas e a outras faixas etárias, em instituições envolventes a Camarate, mas também mais distantes. Seria interessante fazer intercâmbio com escolas onde o grau de poluição luminosa seja menor, para que os alunos pudessem realmente constatar as diferenças do céu noturno, in situ. Deste modo, promovia-se a atualização dos dados na plataforma Globeat Nigth e a construção de mapas de poluição luminosa, considerando as relações entre o local e o global.

- Divulgou a temática a nível nacional, ao participar com escalão 4 ( $3^{\circ}$ ciclo) na $13^{a}$ edição do concurso "Ciência na Escola", promovido pela Fundação Ilídio Pinho, tendo recebido prémio na fase 1 - concurso de ideias e sendo selecionado, na fase 2 - desenvolvimento do projeto, para a Mostra Nacional, na qual participaram os 100 melhores projetos a nível nacional, divididos em 5 
escalões. Durante a Mostra Nacional, realizada nos dias 20 e 21 de setembro de 2016, em Pinhal Novo, distrito de Setúbal, os alunos tiveram a oportunidade de expor a problemática da poluição luminosa a políticos (primeiro ministro e ministro da educação), empresários, professores, assim como a alunos de outros pontos do país.

- A $13^{\mathrm{a}}$ edição do concurso "Ciência na Escola", promovida pela Fundação Ilídio Pinho, inclui, em processo de finalização, a elaboração do Catálogo Digital dos projetos selecionados a nível nacional. Este Catálogo é uma peça chave para a articulação da inovação e do empreendimento escolar com a economia e o desenvolvimento empresarial, pelo que o material didático, desenvolvido no projeto, será divulgado através deste instrumento.

- Pretende contribuir para a melhoria das luminárias existentes na zona envolvente à escola, quer através da sensibilização aos elementos da comunidade educativa, elementos da Camara Municipal de Loures, quer através da projeção de uma solução ao nível de blindagem para diminuir poluição luminosa provocada por luminárias existentes.

O trabalho anteriormente descrito apresenta limitação por não terem sido recolhidos mais dados sobre o impacto das atividades realizadas, no entanto a implementação do projeto deve ser contínua ao longo do tempo, de modo a que tal possa acontecer no futuro.

\section{Referências bibliográficas}

ALMEIDA, A. Que papel para as Ciências da Natureza em Educação Ambiental? Discussão de ideias a partir de resultados de uma investigação. Revista Electrónica de Enseñanza de las Ciencias, v.6, n.3, p.522-537, 2007.

ALMEIDA, G. Poluição luminosa: o desperdício inútil de recursos energéticos. Física e Sociedade, v.35, p.20-22, 2010.

AMPARO, N. Considerações sobre as relações entre ética ecológica e Educação Ambiental. 2007. Disponível em <http://intranet.ufsj.edu.br/rep_sysweb/File>. Acesso em: 28/10/2016.

BLASK, D. E. Melatonin, sleep disturbance and cancer risk. Sleep Med Rev, v.13, p.257-264, 2009.

BUENO, B. A. A. Poluição Luminosa: Impactos Científicos, Ambientais e Educacionais, Monografia apresentada à Faculdade de Física da Universidade Federal de Uberlândia, Universidade Federal de Uberlândia, Faculdade de Física. 2005.

DELIZOICOV, D. Ensino de física e a concepção freireana de educação. Revista Brasileira de Ensino de Física, v.5, n.2, p.85-98, 1983.

DELIZOICOV, D.; ANGOTTI, J. P.; PERNANBUCO, M. M. Ensino de ciências: fundamentos e métodos. São Paulo: Cortez, 2002. 
FERNANDES, G. W.; COELHO, M. S. Desequilíbrio. O impacto ambiental da poluição luminosa. Scientific American Brasil, n.2, p.41-47, 2010.

GAMA, L.; HENRIQUE, A. B. Astronomia na sala aula: por quê?. Revista LatinoAmericana de Educação em Astronomia, n.9, p.7-15, 2010.

GARGAGLIONI, S. R. Análise legal dos impactos provocados pela poluição

luminosa do ambiente. Dissertação (Mestrado em Ciências da Engenharia da Energia) - Universidade Federal de Itajubá, Itajubá, 2007.

GARGAGLIONI, S. Poluição luminosa e a necessidade de uma legislação. ComCiência, n.112, 2009.

GASTON, K. J.; et al. Benefits and costs of artificial night time lighting of the environment. Environ. Rev., v.22, n.1, 2014.

GOOLEY, J. J.; et al. Spectral Resonses of the Human Circadian System depend on the irradiance and duration of exposure to light. Sci Transl Med, v.2, n.2, p.1-9, 2010.

HOLLAN, J. How should the light pollution be controlled: an experience from the Czech Republic. N. Copernicus Observatory and Planetarium in Brno lecture at Ecology of the Night, Brno, República Tcheca. 2003.

HOUSE OF COMMONS. Light Pollution and Astronomy. Science and Technology Committee Publication. v.1, Londres, 2003.

HU, D. N.; ROBERTS, J. E.; WIECHMANN, A. F. Melatonin and Melanoma. In: WATSON, R. R. (Ed.). Melatonin in the Promotion of Health. 2nd ed. London: Taylor and Francis, 2011. p.421-431.

\section{IAC (INSTITUTO DE ASTROFÍSICAS DE CANÁRIAS. La Contaminacion}

Lumínica. Oficina Técnica para la Proteccion de la Calidad del Cielo. Disponível em: <http://www.iac.es/servicios.php?op1=28>. Acesso em 03/10/2016.

IDA (INTERNATIONAL DARK SKY ASSOCIATION). Light pollution and wildlife. Brochure. 2008.

KANTOR, C. A. A ciência do céu: uma proposta para o ensino médio. Dissertação (Mestrado em Ensino de Ciências) - Instituto de Física, Universidade de São Paulo, São Paulo, 2001.

LAN (LABORATÓRIO NACIONAL DE ASTROFÍSICA). Como podemos evitar a Poluição Luminosa?. 2012. Disponível em:<http://www.lna.br/lp/apostila_pl.pdf >. Acesso em: 04/10/2016.

LANGHI, R.; NARDI, R. Interpretando reflexões de futuros professores de física sobre sua prática profissional durante a formação inicial: a busca pela construção da autonomia docente. Investigações em Ensino de Ciências, v.16, n.3, p.403-424, 2011.

LONGCORE, T.; RICH, C. Ecological light pollution. Frontiers in Ecology and the Environment, v.2, n.4, p.191-198, 2004. 
LONGFELLOW, H. W. Impacts of Light Pollution in organisms and ecosystems In: Artificial Light in the Environment. The Royal Commission on Environmental Pollution. 2009.

MCCOLGAN, M W. Light Pollution. NLPIP- Lighting Answers, v.7, n.2, 2007.

PACE, A. Guidelines for the reduction of light pollution. Light Pollution Awareness Group.2000. Disponível em: <http://www.maltastro.org/lpag/index.htm>. Acesso em 23/11/2016.

PAZ GÓMEZ, F.; SANHUEZA, P.; CASTRO, J. D. Pratical Guide for Outdoor Lighting. Efficient lighting and control of light pollution. Sky Quality Protection tecnhical of Chile y Canarias, 2010.

RAJKHOWA, R. Light Pollution and Impact of Light Pollution. International Journal of Science and Research, v.3, n.10, p.861-867, 2014.

SANTOS, W. L. P.; MORTIMER, E. F. Uma análise de pressupostos teóricos da abordagem C-T-S (Ciência-Tecnologia-Sociedade) no contexto da educação brasileira. Ensaio: pesquisa em educação em ciências, v.2, n.2, p.133-162, 2002.

SCHEER, F. A. J. L.; et al. Adverse metabolic and cardiovascular consequences of circadian misalignment. Proc Natl Acad Sci, v.106, n.11, p.4453-4458, 2009.

THURBER, J. There are two kind of light: the glow that illuminates and the glare that obscures. In: Artificial Light in the Environment. The Royal Commission on Environmental Pollution, p.1-4, 2009. 


\section{ANEXO A \\ Auditoria à iluminação Pública - Rua/Escola}

Quantas estrelinhas consegues ver, a olho nu, na rua onde moras? Sabias que no céu existem milhares de milhões de estrelas? Não consegues imaginar um céu assim tão estrelado? Pois é, a culpa é da POLUIÇÃO LUMINOSA. Esse problema crescente resulta principalmente de candeeiros e projetores exteriores que estão mal concebidos ou mal direcionados, iluminando para cima ou para os lados e emitindo luz muito para além do seu alvo, sem qualquer efeito útil. A luz emitida para cima e para os lados reflete-se e difunde-se nas nuvens, poeiras e fumos em suspensão no ar, tornando o céu noturno mais claro. A sua ajuda na "caça" à má iluminação será muito preciosa e poderá ajudar não só a preservação do planeta, mas ao reencontro das pessoas com o bonito céu estrelado.

Questão problema: Que tipo de iluminação pública existe na minha rua/escola?

\section{Morada:}

\section{A. Auditoria na Rua}

Faça um esboço da rua que adotou. Represente por um $\mathrm{X}$ as posições dos candeeiros públicos, indicando a distância a que se encontram. Indique onde está a incidir a iluminação (ex. chão).

\section{B. Auditoria à Escola}

Faça um esboço da planta da escola, à escala, indicando comprimentos e larguras. Represente por um X as posições dos candeeiros públicos, indicando a distância a que se encontram. Indique onde está a incidir a iluminação (ex. chão).

NOTA: Regresse à noite com o seu grupo e confirme onde as luzes incidem. Quais as áreas onde existe défice ou excesso de iluminação, tendo como referência os locais que lhe cabe iluminar. Verifique se as luzes estão a incidir apenas onde é necessário ou se estão bloqueadas pela vegetação ou por outra estrutura. Analise também se existem zonas demasiado brilhantes ou zonas excessivamente escuras, que diminuem a capacidade de observar o que está à sua volta.

\section{Vamos agora analisar cada um dos candeeiros...}

Os candeeiros são todos iguais? Sim Não E as lâmpadas são todas iguais? Sim Não

2. Analisando a Figura 1, faça um círculo nos candeeiros parecidos com os que existem na sua rua/ escola. Tire fotografias de cada tipo de luminária identificada.

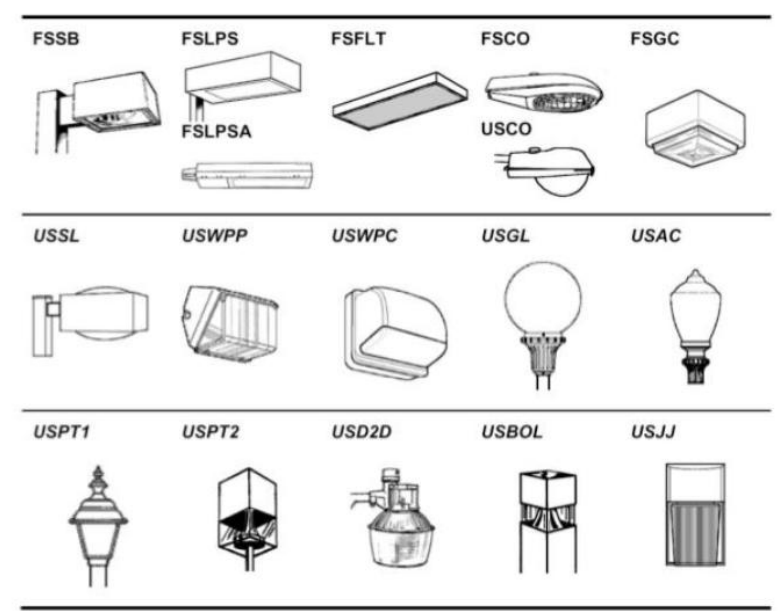

Figura 1- Imagens de diferentes tipos de equipamentos e suas abreviações. 
Poluição luminosa e educação ambiental: um estudo de caso em Camarate, Lisboa

2.1. Caso os candeeiros/lâmpadas da sua rua sejam diferentes dos casos apresentados na Figura 1, desenhe ou tire uma fotografia a cada um desses tipos diferentes de luminárias.

\begin{tabular}{|c|c|c|c|c|c|c|c|c|c|c|c|}
\hline \multirow[t]{2}{*}{ Luminária } & \multirow[t]{2}{*}{$\begin{array}{r}\text { Cor da } \\
\text { lâmpada }\end{array}$} & \multirow[t]{2}{*}{$\begin{array}{l}\text { Tipo de } \\
\text { lâmpada }\end{array}$} & \multirow[t]{2}{*}{ Potência } & \multicolumn{2}{|c|}{$\begin{array}{c}\text { Está } \\
\text { orientada } \\
\text { na posição } \\
\text { correta? }\end{array}$} & \multicolumn{2}{|c|}{$\begin{array}{c}\text { Tem } \\
\text { proteção? }\end{array}$} & \multicolumn{2}{|c|}{$\begin{array}{l}\text { Tem sensor de } \\
\text { movimento? }\end{array}$} & \multicolumn{2}{|c|}{$\begin{array}{c}\text { Tem } \\
\text { temporizador? }\end{array}$} \\
\hline & & & & Sim & Não & Sim & Não & Sim & Não & Sim & Não \\
\hline 1 & & & & & & & & & & & \\
\hline 2 & & & & & & & & & & & \\
\hline 3 & & & & & & & & & & & \\
\hline 4 & & & & & & & & & & & \\
\hline 5 & & & & & & & & & & & \\
\hline 6 & & & & & & & & & & & \\
\hline 7 & & & & & & & & & & & \\
\hline 8 & & & & & & & & & & & \\
\hline 9 & & & & & & & & & & & \\
\hline 10 & & & & & & & & & & & \\
\hline
\end{tabular}

2.2. Caracterize com a ajuda da Figura 1 e dos dados em anexo, cada uma das luminárias identificadas.

Para que os registros da auditoria possam ajudar a rentabilizar o consumo de energia usada na iluminação noturna, é necessário determinar o consumo energético. Esta tarefa vai ser realizada em posteriores aulas de Ciências Físico-químicas e TIC. A informação obtida deve ser divulgada, assim como possíveis soluções de melhoria, junto da direção da escola/órgãos autárquicos pelo que a sua função como Dark Sky Ranger ainda agora começou. 